\title{
Perfil de médicos ginecologistas/obstetras de Londrina com relação à saúde oral da gestante
}

\author{
Profile of Londrina's gynecologists and obstetritians regarding \\ pregnant women's dental health
}

\begin{abstract}
MENOLI, A.P.V.; FROSSARD, W.T.G. Perfil de Médicos Ginecologistas/Obstetras de Londrina com Relação à Saúde Oral da Gestante. Semina, Londrina, v. 18, ed. especial, p. 34-42, fev. 1997.

RESUMO: Esta pesquisa procura estabelecer um perfil dos médicos ginecologistas/obstetras de Londrina com relação à saúde oral de gestantes, a fim de se obter subsídios para traçar um plano de atuação integrada baseado no conceito de promoção da saúde e no contexto de saúde geral Procurou-se definir alguns dados pessoais e formação profissional $e$ identificar procedimentos de rotina de interesse odontológico aplicados às gestantes (exame oral, encaminhamento ao cirurgião dentista, medidas utilizadas para prevenção da cárie $e$ doença periodontal), e ainda conhecimentos acerca de questões odontológicas sobre etiologia da doença periodontal, dieta e suplementação de flúor. A coleta de dados foi feita por meio de entrevistas, através de questionários. Constatou-se que $90 \%$ dos médicos entrevistados relatou avaliar a cavidade oral de suas pacientes gestantes, porém somente a metade adota esse procedimento como rotina; que o controle dietético é largamente utilizado visando manutenção do peso da gestante; que a prescrição de flúor sistêmico é uma prática comum e o veículo mais indicado são os polivitamínicos; e que a maioria dos médicos afirma não ter recebido qualquer tipo de orientação sobre saúde oral em sua graduação ou pós-graduação.

PALAVRAS-CHAVE: Gravidez; Cuidado Pré-Natal; Prevenção; Educação em Saúde Bucal.

ABSTRACT: This research aims at establishing a profile of the gynecologists/obstetricians from Londrina regarding the pregnant women $s$ dental health, in order to obtain support
\end{abstract}

Ana Paula Vicen'^Menoli* Wanda T. Garbelini Frossard**

* Autora: Aluna do $5^{\circ}$ ano de Graduação em Odontologia da Universidade Estadual de Londrina.

* Orientador: Mestre em Odontopediatria, Prof Adjunto de Odontopediatria da Universidade Estadual de Londrina/Centro de Ciências da Saúde- rua Pernambuco, 540 Fone (043) 321-2002 - CEP 86020-070 - Londrina - Paraná. 


\begin{abstract}
to build up an integrated plan of action based on the concept of health promotion as well as on the context of general health Attempts were made to define some personal data and professional background and to identify procedures of dental interest routine applied to the pregnant woman (oral exam, forwardness to the dental surgeon, precautions for the cavity prevention and periodontal disease), as well as to knowledge about dental issues (etiology of the periodontal disease, diet and fluoride supplement). The data collection was done by means of interviews/questionnaires. The conclusion drawn was that most of the physicians who were interviewed evaluate the oral cavity of their pregnant patients, but only half of them adopt this procedure as a routine; that the dietary control is widely used aiming at maintaining the pregnant woman $s$ weight; that prescription of systematic fluoride is usual habit and the most appropriate means for achieving that is the use of polyvitamins; and most physicians state that they never received any kind of orientation about dental health during their undergraduate or graduate program.

KEY WORDS: Pregnancy; Prenatal Care; Prevention; Dental Health Education
\end{abstract}

\section{INTRODUCÃO}

O tratamento preventivo continua sendo a arma mais eficaz no combate aos problemas dentários.

Não há dúvida de que a única proposta viável para a diminuição desses problemas é a motivação mediante conscientização e educação do paciente que passa assim a exercer papel ativo nos programas preventivos ${ }^{2+412}$.

Alcançar uma mudança comportamental, contudo, é uma tarefa árdua.Um grupo altamente susceptível a receber informações e incorporar novas atitudes são as gestantes, visto que a futura mãe está ávida por proporcionar o máximo bem estar a si mesma, e por conseqüência, ao futuro filho ${ }^{15}$.

Entendemos portanto que o ginecologista/obstetra é um importante vetor para a transmissão da educação, já que é o profissional de saúde que mantém o primeiro e maior contato com a gestante exercendo forte poder de influência sobre ela.

ELVEY E HEWIE (1982) recomendam justamente que a educação comece com a gestante. Viabilizar acesso a informações, mudanças de hábitos e atitudes da mãe significa garantir precocemente a saúde de seu filho.

Se é pertinente ao obstetra atuar junto à gestante instruindo-a acerca das precauções que deve ter para manter sua saúde oral, cabe-lhe também a responsabilidade de orientá-la e como assegurar à futura criança a possibilidade de que venha a ter dentes mais resistentes à cárie ${ }^{11}$.

Com muita razão, as medidas preventivas das doenças mais prevalentes da cavidade oral: cárie e doença periodontal começam antes da criança nascer. Este axioma parece sintetizar toda a filosofia do moderno conceito da odontologia preventiva que pressupõe uma abordagem interdisciplinar e multiprofissional na detecção, prevenção e solução de problemas.

A higiene pré-natal deve funcionar como um todo, de tal forma entrosada, que nenhum setor preventivo ou terapêutico possa ser considerado dispensável ou objeto de menores cuidados ${ }^{4}$. Portanto, os problemas 
odontológicos da mulher, exacerbados durante a gestação devido à negligência na higienização bucal, alterações na dieta, náuseas, vômitos e hiperacidez do meio bucal são parte integrante do atendimento pré-nata $a^{12}-{ }^{6}-{ }^{14}$.

O objetivo deste estudo é estabelecer um perfil dos médicos ginecologistas/obstetras de Londrina com relação à saúde oral da gestante, a fim de se obter subsídios para traçar um plano de atuação integrada baseado no conceito de promoção da saúde e no contexto de saúde cerai.

\section{MATERIAL E MÉTODO}

O estudo foi realizado com 90 médicos ginecologistas/obstetras que exercem suas atividades na cidade de Londrina, segundo dados da Associação Médica local.

As entrevistas, por meio de questionários, foram realizadas no período de setembro e outubro de 1996.

Após essa fase, considerando-se as perdas com questionários não devolvidos e recusas a respondê-los, contamos com 69 médicos ou $76,6 \%$ da população inicial para a tabulação de dados.

Para a obtenção de informações, foram elaboradas perguntas com dados sobre identificação do profissional, identificação de procedimentos de rotina de interesse odontológico aplicados às gestantes (exame oral, encaminhamento ao cirurgião-dentista, medidas utilizadas para prevenção da cárie e doença periodontal); e ainda sobre formação profissional e conhecimentos acerca de questões odontológicas sobre etiologia da doença periodontal, dicta e suplementação de flúor.

As questões eram semi-abertas e foram analisadas quantitativamente.

O questionário foi validado com 2 médicos, o que permitiu fazer as adequações necessárias nas questões, envolvendo seleção de palavras, definição do tamanho do questionário e forma das questões.

Os dados foram arquivados e tabulados no programa Epi infoó versão 6.02 e posteriormente analisados de forma descritiva (tabelas, figuras, mediana, valor mínimo e máximo).

\section{RESULTADOS}

TABELA 1 - Distribuição dos médicos ginecologistas/obstetras em relação às estruturas avaliadas durante o exame oral - 1996

\begin{tabular}{lll}
\hline ESTRUTURAS AVAliadas & $\mathrm{N}$ & $\mathrm{f}(\%)$ \\
\hline Dentes & 50 & 80,6 \\
Gengiva & 51 & 82,3 \\
Mucosa Oral & 43 & 69,4 \\
Língua & 40 & 64,5 \\
Amígdalas & 43 & 69,4 \\
Outros & 6 & 9,6 \\
TOTAL & 62 & 100 \\
\hline
\end{tabular}

Fonte: Ginecologistas e obstetras de Londrina

TA B ELA 2 - Distribuição dos médicos ginecologistas/obstetras de acordo com as medidas preventivas adotadas para controle da cárie e doença periodontal - 1996

\begin{tabular}{lcc}
\hline MEDIDAS & $\mathrm{N}$ & $\mathrm{f}(\%)$ \\
\hline Instrução de Higiene Oral & 50 & 81,9 \\
Orientação Alimentar & 28 & 45,9 \\
Visita ao CD. Antes da Gravidez & 1 & 1,6 \\
Visita Regular ao C.D. & 5 & 8,2 \\
Visita ao C.D. se Necessário & 13 & 21,3 \\
Suplemento Vitamínico e/ou & & \\
Flúor e/ou Cálcio & 15 & 24,5 \\
TOTAL & 61 & 100 \\
\hline
\end{tabular}

Fonte: Ginecologistas e obstetras de Londrina. 
TABELA 3 - Distribuição dos médicos ginecologistas/obstetras à questão: "Em relação a doença periodontal, você considera como fatores etiológicos:" 1996.

\begin{tabular}{lrr}
\hline FATOR ETIOLÓGICO & N & $\mathrm{f}(\%)$ \\
\hline Má Higiene Oral & 64 & 92,8 \\
Gravidez & 31 & 44,9 \\
Freqüência de Consumo de Açúcar & 17 & 24,6 \\
Quantidade Consumida de Açúcar & 9 & 13,0 \\
Outros & 3 & 4,3 \\
NR & 2 & 2,8 \\
TOTAL & 69 & 100 \\
\hline
\end{tabular}

Fonte: Ginecologistas e Obstetras de Londrina.

TABELA 4 - Distribuição dos médicos ginecologistas/obstetras em relação aos motivos para orientação do consumo de açúcar - 1996

\begin{tabular}{lcc}
\hline MOTiVo & N & $\mathrm{f}(\%)$ \\
\hline Peso da Gestante & 53 & 86,9 \\
Problemas Sistêmicos da Gestante & 48 & 78,7 \\
Saúde Bucal da Gestante & 31 & 50,8 \\
Saúde do Feto & 1 & 1,6 \\
TOTAL & 61 & 100 \\
\hline
\end{tabular}

Fonte: Ginecologistas e Obstetras de Londrina.

TABELA 5 - Distribuição dos médicos ginecologistas/obstetras em relação à prescrição de suplementos de flúor, veículo utilizado, critérios e alvo - 1996.

\begin{tabular}{|c|c|c|c|c|c|}
\hline PRESCRIÇÃO & $\mathrm{N}$ & $\mathrm{f}(\%)$ & CRITÉRIO & $\mathrm{N}$ & $\mathrm{f}(\%)$ \\
\hline Sim & 36 & 52,2 & História de Cárie & 2 & 3,3 \\
\hline Às Vezes & 24 & 34,8 & Nível de Flúor & & \\
\hline & & & da Água & 22 & 36,7 \\
\hline \multirow[t]{3}{*}{ Não } & 9 & 13,0 & \multicolumn{3}{|l|}{ Medida Preventiva } \\
\hline & & & de Rotina & 44 & 73,3 \\
\hline & & & NR & 2 & 3,3 \\
\hline TOTAL & 69 & 100 & TOTAL & 60 & 100 \\
\hline VEÍCULO & $\mathrm{N}$ & $f(\%)$ & ALVO & $\mathrm{N}$ & $\mathrm{f}(\%)$ \\
\hline Polivitamínicos & 58 & 96,7 & Gestante & 9 & 15,8 \\
\hline Puro & 1 & 1,7 & Bebê & 9 & 15,0 \\
\hline \multirow[t]{2}{*}{ NR } & 1 & L7 & Ambos & 40 & 66,7 \\
\hline & & & NR & 2 & 3,3 \\
\hline TOTAL & 60 & 100 & TOTAL & 60 & 100 \\
\hline
\end{tabular}

Fonte: Ginecologistas a Obstetras de Londrina
TA B ELA 6 - Distribuição dos médicos ginecologistas/obstetras segundo orientação profissional relacionada à saúde oral - 1996

\begin{tabular}{|c|c|c|c|c|c|c|c|c|c|c|}
\hline \multirow{3}{*}{$\begin{array}{l}\text { ENTIDADE DE } \\
\text { GRADUAÇÃO }\end{array}$} & \multirow{3}{*}{$\mathrm{N}$} & \multirow{3}{*}{$\mathrm{f}(\%)$} & \multicolumn{4}{|c|}{$\begin{array}{c}\text { RECEBEU } \\
\text { ORIENTAÇÃOO }\end{array}$} & \multicolumn{4}{|c|}{$\begin{array}{l}\text { ORIENTAÇÃO FOI } \\
\text { SUFICIENTE }\end{array}$} \\
\hline & & & \multicolumn{2}{|c|}{ SIM } & \multicolumn{2}{|c|}{ N ÃO } & \multicolumn{2}{|c|}{ SIM } & \multicolumn{2}{|c|}{ N Ã O } \\
\hline & & & $\mathrm{N}$ & TO & $\mathrm{SN}$ & TO & $\mathrm{N}$ & TO & $\mathrm{N}$ & TO \\
\hline UEL & 47 & 68,1 & 9 & 13,0 & 38 & 55,8 & 3 & 4,3 & 6 & 8,7 \\
\hline OUTROS & 22 & 31,8 & 14 & 20,3 & 7 & 10,1 & 7 & 10,1 & 7 & 10,1 \\
\hline TOTAL & 69 & 100 & 23 & 33,3 & 46 & 66,7 & 10 & 14,5 & 13 & 18,8 \\
\hline
\end{tabular}

Fonte: Ginecologistas e Obstetras de Londrina.

\section{DISCUSSÃO}

Sabe-se que existe uma relação entre o estado gravídico e afecções bucais ${ }^{216}{ }^{910144}$. Somando-se a isso, o fato da gestante carregar dentro de si um ser em formação e desenvolvimento a faz merecedora de atenção odontológica ímpar ${ }^{2}$. Esta atenção deve estar voltada tanto para o aspecto curativo quanto para o educativopreventivo, já que as mães determinam o padrão de comportamento da criança ${ }^{15}$.

O ginecologista/obstetra tem o privilégio de estar ao mesmo tempo em contato com o binômio mãe-filho, o que evidencia a importância de sua participação como agente vetorial da educação, atuando diretamente sobre a mãe e através desta sobre o bebê.

Desta forma, apresenta especial interesse conhecer o padrão dos exames pré-natais no contexto saúde geral da paciente.

A avaliação habitual ou não da boca da gestante pelos médicos, encontra-se ilustrado na Figura 1.

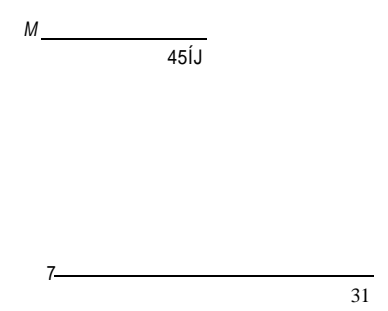

FIGURA 1 - Distribuição dos médicos ginecologistas/obstetras em relação ao exame da cavidade oral das gestantes, Londrina, 1996. 
Na Tabela 1 são expressas as estruturas orais observadas no momento do exame. Dos 69 profissionais, $31(45 \%)$ afirma avaliar rotineiramente a boca de suas pacientes, $31(45 \%)$ afirma que o exame é realizado ocasionalmente (às vezes), e 7 (10\%) diz não praticá-lo. Em relação às estruturas orais examinadas, os resultados indicaram que maior importância é dada à observação de gengivas $(82,3 \%)$ e dentes $(80,6 \%)$. Mucosa oral e amígdalas são avaliados por $69,4 \%$ dos entrevistados e a língua por $64,5 \%$. Ainda, 9,6\% diz considerar outras estruturas (faringe, palato, lábios)

$\mathrm{Na}$ literatura, vários trabalhos levantam a preocupação de uma abordagem integral em relação a saúde do paciente ${ }^{4}$, ainda mais em um período único e peculiar como a gravidez pois sabe-se que na gestação ocorre uma exacerbação de certas perturbações da cavidade oral na presença de fatores predisponentes ${ }^{14}$.

O exame de dentes, portanto, é válido já que perturbações de saúde oral na gravidez causam prejuízos à saúde da gestante e ao feto. Assim, embora a gestação em si não seja mais propícia à incidência de cárie que outras condições de vida, a má saúde oral tem conseqüências mais graves nesse período, devendo ser convenientemente preservada sua sanidade ${ }^{4}$. Por esta ótica, o exame de gengivas é também indispensável. É comum a mulher desconhecer que possui uma gengivite crônica moderada, mas quando engravida este fator desperta atenção, pois as gengivas podem mudar de aparência devido a alterações hormonais ${ }^{4}$.

De modo geral, as infecções orais e periodontopatias constituem riscos para a gestante e para o feto, ocasionando quase sempre desconforto psico-físico . É portanto desejável que maior número de médicos utilize o exame bucal de rotina durante o pré-natal, a fim de prevenir ou interceptar tais quadros.

Sabemos, contudo, que há lacunas no ensino ao abordar conteúdos de forma multiprofissional e interdisciplinar, o que incapacita o médico de intervir na cavidade oral. E portanto desejável que ele encaminhe a paciente ao consultório odontológico para receber tratamento especializado

A Figura 2 procura justamente apresentar as circunstâncias em que as pacientes gestantes são orientadas, pelos médicos, a visitar o cirurgião-dentista (C.D.)

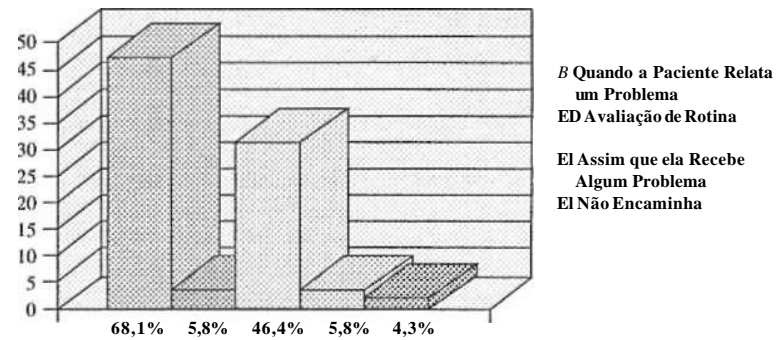

FIGURA 2 - Distribuição dos médicos ginecologistas/obstetras de acordo com o encaminhamento da paciente ao cirurgião-dentista, Londrina, 1996.

Encontrou-se que $68,1 \%$ dos profissionais entrevistados encaminha suas pacientes grávidas ao CD assim que a mesma relata algum problema; 46,4\% dos médicos recomenda avaliação do dentista quando ele próprio percebe algum problema; 5,8\% não encaminha a gestante para supervisão odontológica e 5,8\% utiliza esse procedimento como rotina.

Atualmente os conceitos de prevenção se baseiam na promoção de saúde. Dessa forma, a maioria dos médicos entrevistados $(68,1 \%)$ não contribui para que suas pacientes tenham acesso a qualidade total em saúde, uma vez que são encaminhados ao CD. já com algum quadro sintomatológico.

O raro encaminhamento das gestantes ao CD. como procedimento de rotina, contradiz contudo, a opinião dos médicos sobre a propensão da mulher, neste estado especial, adquirir certas patologias. No grupo entrevistado, 95,6\% considera probabilidade de adquirir cárie e/ou doença periodontal aumentada durante a gestação. 
De fato, GLICKMAN ${ }^{9}$ (1983) observou que na gravidez há uma tendência a reações gengivais exageradas frente a irritações locais. ZISKIN (1966) apud $\mathrm{CUNHA}^{5}$ (1985), estudando 416 gestantes encontrou gengivite em 37,9\%. FRASER (1944) apud GLICKMAN" (1983) encontrou prevalência de 53,8\%, CUNHA $(1985)$ de $52,5 \%$.

Em relação à cárie dentária, não se associa a gestação a esta infecção ${ }^{14}$.

BODECKER (1931), DAY (1933) e APPLEBAUM (1931) apud RAMALHO ${ }^{14}$ (1968) afirmaram ter observado um aumento de cárie durante a gravidez. A maioria dos autores, segundo VIEGAS ${ }^{17}$ (1970), desconsidera porém, que alterações hormonais e hiperacidez salivar sejam suficientes para causar cárie dentária. Sua maior incidência durante a gravidez é motivada pela negligência de tratamento ${ }^{4}-{ }^{6}$.

Considerando-se a opinião dos médicos ginecologistas/obstetras sobre maior prevalência de gengivite e cárie na gestante, interessa saber a quais medidas recorrem para prevenir tais quadros indesejáveis. Esses achados estão expressos na Tabela 2, onde 61 médicos afirmam fazer uso de medidas preventivas, sendo que $8,2 \%$ recomendam visita regular ao dentista; $21,3 \%$ visita ao dentista se necessário; $1,6 \%$ visita ao odontólogo antes da gravidez; 4,5\% suplemento vitamínico, e/ou flúor e/ou cálcio e ainda $81,9 \%$ mencionam orientação de higiene e $45,9 \%$ orientação alimentar.

Alguns procedimentos citados são, imprescindíveis para a manutenção da saúde bucal (combater o agente microbiano, aumentar a resistência dos dentes pelo uso de flúor, controle da dieta) ${ }^{12}$.

Pesquisas clínicas na Escandinávia demonstraram que a visita regular ao dentista para limpeza dentária profissional pode produzir uma dramática redução da doença dental ${ }^{12}$.

A orientação alimentar tem papel chave na prevenção da cárie dentária, uma vez que evidências circunstanciais unindo o consumo de sacarose à prevalência da cárie dental podem ser prontamente encontradas em pesquisas epidemiológicas ${ }^{12}$.

Essas medidas, em toda sua eficácia e simplicidade são ainda pouco utilizadas pelos médicos em relação a suas pacientes, apesar de considerá-las susceptíveis à cárie e doença periodontal.

A orientação de higiene oral é a medida mais utilizada como método preventivo $(68,9 \%)$. De fato, a toalete oral está ligada à prevalência da doença periodontal ${ }^{16}$. $\mathrm{Na}$ gestante, a orientação de higiene tem não só um efeito benéfico direto sobre a mãe, como também sobre o bebê.

TSAMTSOURIS $^{15}$ (1986) expõe com propriedade a importância da educação dental para futuros pais. Segundo ele as mães determinam o padrão de comportamento da criança e este fator deve ser trabalhado no pré-natal aproveitando-se o entusiasmo com a chegada do bebê, o que propicia receptividade para receber novas informações e assumir responsabilidades.

O fato da orientação de higiene oral ser o método preventivo de afecções bucais mais utilizado, condiz com a opinião dos médicos sobre a etiologia da doença periodontal, como mostra a Tabela 3 .

Dos entrevistados, $92,8 \%$ relaciona a doença periodontal à má higiene, 44,9\% à gravidez, 24,6\% relaciona à freqüência consumida de açúcar e $13 \%$ à quantidade consumida.

A etiologia do problema periodontal também tem sido objeto de inúmeras pesquisas. Nos primeiros estudos em 1933 de ZISKIN apud RAMALHO ${ }^{18}$ (1968) concluiu-se que a gengivite na gravidez tinha como causa única uma alteração hormonal. Contrário a ZISKIN, UGOSON (1970) apud CARVALHO² (1986) observou que devido a elevações nas taxas de progesterona, há alterações na microvascularização que se traduz na gengiva por um aumento da inflamação na presença da placa bacteriana. Esta teoria é hoje aceita pela maioria dos autores. Do ponto de vista teórico, a completa remoção diária da placa reduziria pronunciadamente o aumento de novas lesões cariosas e da doença gengival ${ }^{12}$.

Como já foi exposto anteriormente, há riscos inerentes ao consumo de alimentos contendo sacarose. Este hábito favorece não apenas a cárie dentária, como também acarreta uma ingestão calórica elevada, indesejável para pessoas com excesso de pesol2. Constitui-se então um ponto importante verificar as orientações que as gestantes recebem em relação ao consumo de açúcar e suas justificativas.

Pela Figura 3, verifica-se que, dos 69 médicos 
entrevistados, apenas $7(10,1 \%)$ não fazem qualquer tipo de orientação. Maior percentagem faz orientação em relação à quantidade consumida de açúcar $(75,4 \%)$, seguida da freqüência de consumo $(63,8 \%)$ e tipo de açúcar ingerido $(26,1 \%)$.
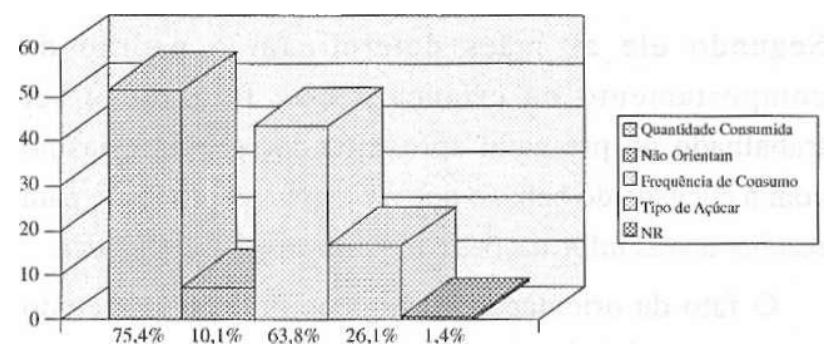

FIGURA 3 - Distribuição dos médicos ginecologistas/obstetras em relação à orientação para consumo de açúcar, Londrina, 1996

Uma comparação entre os dados da Figura 3 e Tabela 4, permite relacionar recomendações referentes à quantidade e freqüência do consumo de açúcar com a preocupação com o peso da gestante e problemas sistêmicos. A preocupação com a saúde oral aparece em 3 o lugar, mencionada por 31 (45\%) médicos.

Está claro que a sacarose exerce papel chave como substrato no processo cárie. Influenciam o processo a forma, tipo, quantidade e especialmente freqüência do consumo de açúcar ${ }^{12}$. NEWBRUN ${ }^{12}$ (1988) afirma que, onde existe livre escolha e acesso a alimentos e bebidas doces, tais itens são consumidos entre as refeições.

De fato, esta tendência se observa na gestante que, devido a menor capacidade fisiológica do estômago, passa a consumir menor quantidade de alimentos por vez, fragmentando as refeições ${ }^{10113}$.

A Organização Mundial de Saúde (OMS) em seu boletim "Saúde para todos no Ano 2000" citado por CUNHA $^{s}$ (1985) preconiza que a gestante evite alimentos açucarados durante a gravidez. Ela deve ser informada de que a partir do 40 mês de gestação começa a se desenvolver o paladar do bebê. Se nessa fase a mãe comer muito açúcar, certamente seu filho irá gostar muito de doces.

Mudanças de hábitos só irão beneficiar mãe e filho.

A Tabela 5 tem por objetivo demonstrar algumas características da prescrição de fluoretos pelos ginecologistas

$\mathrm{Na}$ análise geral, apenas 9 médicos (13\%) não prescrevem flúor sistêmico. Dos 60 que o fazem, 36 $(52,2 \%)$ o fazem sempre, e $24(34,8 \%)$ às vezes, embora o veículo utilizado seja em $96,7 \%$ dos casos o mesmo: um polivitamínico. Como critérios para a prescrição, 2 (3,3\%) médicos levam em consideração história de cárie, $22(32,7 \%)$ o nível de flúor da água de abastecimento e $44(73,3 \%)$ dizem utilizar o flúor como medida preventiva rotineira. E interessante que em $66,7 \%$ dos casos, a suplementação visa atingir mãe e bebê. O efeito anticariogênico do flúor é hoje inquestionável. Nos últimos quarenta anos, numerosas são as publicações que correlacionam a redução do índice de cárie à administração do flúor pós-natal, tanto por via sistêmica como nas formas tópicas ${ }^{8}$. Os benefícios da fluoretação pré-natal, contudo, têm sido seriamente questionados ${ }^{118}{ }^{14}$

BLANEY e HILL, TANK e STOVICK apud FASSMAN $^{8}$ (1993) pressupõem que a somatória do uso de fluoretos pré e pós-natal, através do consumo de água fluoretada, aumenta a proteção dos dentes decíduos do feto. KAILIS, PRICHARD, GLENN apud FASSMAN (1993) relatam ainda um incremento na proteção de dentes decíduos e lo molar permanente quando ocorre a suplementação de flúor pré-natal. BASTOS ${ }^{1}$ et al (1985) sublinha, contudo, que quando o veículo utilizado para a suplementação é um polivitamínico, seu efeito é desprezível do ponto de vista anticariogênico, tanto para a mãe como para o filho, pela dose de flúor contido estar abaixo do ideal.

Esta afirmativa desperta maior interesse ao se observar na Tabela 5 que: 60 (87\%) médicos fazem suplementação, destes $58(96,7 \%)$ usam polivitamínicos, 
$40(66,7 \%)$ usam estas medidas pensando na mãe e no filho e $44(73,3 \%)$ justificam a suplementação como procedimento de rotina. Faz-se necessário, então, que todos os conhecimentos acerca do flúor sejam analisados em conjunto para embasar a prescrição ou invalidá-la.

A formação acadêmica tem papel importante no modo de atuação dos profissionais da área da saúde. Resta-nos avaliar qualitativa e quantitativamente a formação acadêmica e de pós-graduação que os médicos ginecologistas/obstetras receberam no tocante a saúde bucal.

Dos médicos entrevistados que clinicam em Londrina, $47(68,1 \%)$ se graduaram nessa mesma cidade. Desses, $38(55,8 \%)$ afirmam não ter recebido orientação sobre saúde oral. Dos $9(13 \%)$ que tiveram acesso a esse conteúdo, apenas $3(4,3 \%)$ consideraram que a abordagem foi satisfatória (Tabela 6).

O conteúdo saúde oral, nos currículos médicos, é uma lacuna a ser preenchida através de abordagem interdisciplinar e multiprofissional dos conhecimentos para viabilizar, em relação à saúde dos indivíduos, ações de caráter integral.

Afinal, é imprescindível que o paciente seja visto como um todo, e no caso da gestante, que esse todo se multiplique por dois.

\section{CONCLUSÃO}

Através deste estudo, foi possível concluir que:

- a maioria dos médicos ginecologistas/obstetras entrevistados afirma avaliar a cavidade oral de suas pacientes gestantes, porém somente a metade adota este procedimento como rotina.

- a maior parte dos médicos pesquisados encaminha a paciente ao dentista quando a mesma relata algum problema. Pouquíssimos adotam essa medida como rotina.

- maior probabilidade da gestante adquirir cárie e/ou doença periodontal é uma afirmativa amplamente aceita na população estudada.
- orientação à gestante sobre higiene oral é procedimento difundido entre os médicos entrevistados, bem como a má higiene é fator etiológico da doença periodontal.

- o controle dietético é largamente recomendado às gestantes com ênfase para a redução da quantidade de açúcar, visando primordialmente manutenção do peso.

- a prescrição de flúor sistêmico como rotina é uma prática mais que comum entre os ginecologistas/obstetras entrevistados. A maioria indica o uso de polivitamínicos e visa ação na mãe e no bebê.

- um número muito significativo de médicos ginecologistas/obstetras atuantes nesta cidade afirma não ter recebido qualquer tipo de orientação sobre saúde oral em sua graduação ou pós-graduação. 


\section{REFERÊNCIAS}

\section{BIBLIOGRÁFICAS}

01. BASTOS, J.R.M.; BASSANI, A.C.; LOPES, E.S. Prescrição de flúor para gestantes e crianças. $R G O$, Porto Alegre, v.33, n.1, p. 79-83, jan/mar. 1995

02. CARVALHO, E.M.C. Abordagem odontológica durante a gestação. Rev. da Fac. Odont. da $U F B a$, Salvador, v.6, jan/dez. 1986.

03. COUT, J.L.; COUTO, R.S.; DUARTE, CA Motivação do pacientte. RGO, Porto Alegre, v.40, n.2, p.143-150, mar./abr 1992.

04. COZZUPOLI, CA. Odontologia na gravidez. 3.ed. São Paulo: Panamed, 1981. 154p.

05. CUNHA, M.B.; SAN 'ANNA, D.; CUNHA, J.J. Prevalência da Gengivite na gestante. RBO, Rio de Janeiro, v.42, n.1,2 e 3, p.3-7,jan/jun. 1995.

06. DEAN, A . Get al. Epi info, version 5: a word processing, database, and statistics program for epidemiology on micro-computers. Atlanta, Centers for Disease Control, 1990.

07. DUAlibi, S.E.; DUAlibi, M.I. A odontologia para a gestante. Rev. Paul. Odont., São Paulo, v.7, n.5,p.12-36, set/out. 1985 .

08. ELVEY. S.M.; HEWIE. S.P.A. A avaliação dentária feita pelo pediatra. Clin. Pediat. Amer. N., Philadelfia,p.833-41,jun. 1982.

09. FASSMAN, D.K. Prenatal fluoridation: A literature Review. N.Y. State Dent. J., New York, v.59, n.6,p.47-51,jun/jul. 1993.

10. GlickMAN, I. Periodontia Clínica. 7.ed. Rio de Janeiro: Panamericana, 1983. 468p.

11. KRASSE, B. Risco de cáries. 2.ed. São Paulo: Quintessence, 1988. 113p.
12. MARCONDES, E. Pediatria Básica. 4.ed. São Paulo: Darvier, 1973. 383p.

13. NEWBRUN, E. Cariologia. 2.ed. São Paulo: Santos, 1988. 326p.

14. OlIVEIRA, M.A.M. Atendimento Odontológicona gravidez: considerações clínicas e emprego de medicamentos. São Paulo: Santos, 1990. 60p.

15. RAMALHO, A. Odontologia e obstetrícia: problemas odontológicos relacionados com a gravidez. São Paulo: Fonseca, 1968. 129p.

16. TSAMTSOURIS, A.; STACK, A.; PADAMSEE, M. Dental Education of expectant parents. /. Pedodont, Boston, v.10, n.4, p.309-22, Summer. 1986.

17. VIEGAS, A.R. Odontologia Preventiva. São Paulo, 1965.

18. VIEgAS, Y. Gestação e cárie dental. Rev. Saúde Pública, São Paulo, v.4, n.1, p.71-7, jun.1970. 